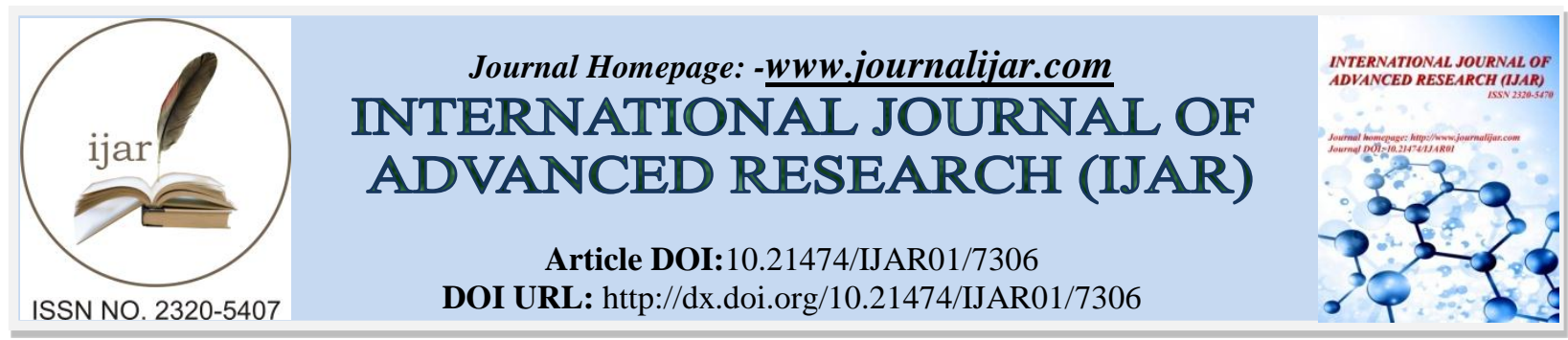

RESEARCH ARTICLE

\title{
CLONING OF LIPASE GENE ISOLATED FROM BACILLUS SUBTILIS 168 INTO THE E.COLI DH5A HOST.
}

\author{
Ahmed N. Abdulwahb, Anwer Jaber Faisal Faisal, Baraa Ahmed Saeed Saeed. \\ 1. Dept. of Biology, Bangalore University, India. \\ 2. Dept. of Biology, Al-Farabi University College, Baghdad, Iraq.
}

\section{Manuscript Info}

(..........................

Manuscript History

Received: 17 April 2018

Final Accepted: 19 May 2018

Published: June 2018

Keywords:-

Lipase Gene, Bacillus subtilis 168, E.coli DH5 $\alpha$ Host.

\section{Abstract}

Lipase gene was aimed to be cloned from Bacillus subtilis 168 into the E.coli DH5a host. The strain of Baciilus subtilis 168 is ordered from the ATCC . primer designing was done by obtaining a sequence of the lipase gene from NCBI website, A fragment of lipase gene 212 bp in size was obtained using a pair of highly degenerate primers (estA FP and estA RP). the primers are designed to amplify the lipase gene from Bacillus subtilis 168 The used primers have the restriction sites on both ends for restriction enzymes ( BamHI and EcoRI). The targeted gene (lipase) was carried on a plasmid (PUC18) . PUC 18 plasmid was isolated from E.coli DH5 Alpha which has a poly linker sequence located within the lacZ $\alpha$ provides several (10 in case of $\mathrm{pUC18} / \mathrm{pUC19}$ ) unique restriction sites for DNA insertion. The unique restriction sites used for integration of lipase gene insertion into pUC18 vectors interrupt the lacZ $\alpha$ fragment so that appropriate $E$. coli cells possessing recombinant pUC DNA are $\beta$-galactosidase deficient and, as a result, produce white colonies on X-gal medium. The PCR product was successfully amplified by using optimizes PCR cycle. Competent cell preparation was done by using calcium chloride method, Positive transformants shows white colonies with associated antibiotic agar after overnight incubation at $37{ }^{\circ} \mathrm{C}$. The positive clones were streaked onto $\mathrm{X}$-gal medium agar to screen for true lipase producers and were incubated overnight at $37{ }^{\circ} \mathrm{C}$. The recombinant clones formed an intense white color on the X-gal medium agar plate. The aim of the project is to ensure a successful transformation and expression of lipase gene that is used various applications ex: detergent industry and medical purposes etc. as the E. coli generation time has a faster growth rate and more stable than Bacillus spp.

Copy Right, IJAR, 2018,. All rights reserved.

\section{Introduction:-}

Molecular cloning refers to the process of making multiple molecules. Cloning is commonly used to amplify DNA fragments containing whole genes, but it can also be used to amplify any DNA sequence such as promoters, noncoding sequences and randomly fragmented DNA. It is used in a wide array of biological experiments and practical applications ranging from genetic fingerprinting to large scale protein production. Occasionally, the term cloning is 
misleadingly used to refer to the identification of the chromosomal location of a gene associated with a particular phenotype of interest, such as in positional cloning. In practice, localization of the gene to a chromosome or genomic region does not necessarily enable one to isolate or amplify the relevant genomic sequence. To amplify any DNA sequence in a living organism, that sequence must be linked to an origin of replication, which is a sequence of DNA capable of directing the propagation of itself and any linked sequence. However, a number of other features are needed and a variety of specialized cloning vectors (small piece of DNA into which a foreign DNA fragment can be inserted) exist that allow protein expression, tagging, single stranded RNA and DNA production and a host of other manipulations. ${ }^{(1,2)}$

Cloning of any DNA fragment essentially involves four steps

1. Fragmentation - breaking apart a strand of DNA

2. Ligation - gluing together pieces of DNA in a desired sequence

3. Transfection - inserting the newly formed pieces of DNA into cells

4. Screening/selection- selecting out the cells that were successfully transfected with the new DNA

\section{Cloning By A Plasmid:-}

Plasmids are circular, double-stranded DNA (dsDNA) molecules that are separate from a cell's chromosomal DNA. These extra chromosomal DNAs, which occur naturally in bacteria, yeast, and some higher eukaryotic cells, exist in a parasitic or symbiotic relationship with their host cell. Plasmids range in size from a few thousand base pairs to more than 100 kilobases (kb). Like the host-cell chromosomal DNA, plasmid DNA is duplicated before every cell division. During cell division, at least one copy of the plasmid DNA is segregated to each daughter cell, assuring continued propagation of the plasmid through successive generations of the host cell. ${ }^{(3)}$

The plasmids most commonly used in recombinant DNA technology replicate in E.coli. Generally, these plasmids have been engineered to optimize their use as vectors in DNA cloning. For instance, to simplify working with plasmids, their length is reduced; many plasmid vectors are only $\approx 3 \mathrm{~kb}$ in length, which is much shorter than in naturally occurring E. coli plasmids. (The circumference of plasmids usually is referred to as their "length," even though plasmids are almost always circular DNA molecules.) Most plasmid vectors contain little more than the essential nucleotide sequences required for their use in DNA cloning: a replication origin, a drug-resistance gene, and a region in which exogenous DNA fragments can be inserted.

\section{Plasmid DNA Replication:-}

The replication origin (ORI) is a specific DNA sequence of $50-100$ base pairs that must be present in a plasmid for it to replicate. Host-cell enzymes bind to ORI, initiating replication of the circular plasmid. Once DNA replication is initiated at ORI, it continues around the circular plasmid regardless of its nucleotide sequence. Thus any DNA sequence inserted into such a plasmid is replicated along with the rest of the plasmid DNA; this property is the basis of molecular DNA cloning. ${ }^{(4,2)}$

\section{Selection of Transformed Cells;-}

In 1944, O. T. Avery, C. M. Macleod, and M. McCarty first demonstrated gene transfer with isolated DNA obtained from Streptococcus pneumoniae. This process involved the genetic alteration of a bacterial cell by the uptake of DNA isolated from a genetically different bacterium and its recombination with the host-cell genome. Their experiments provided the first evidence that DNA is the genetic material. Later studies showed that such genetic alteration of a recipient cell can result from the uptake of exogenous extrachromosomal DNA (e.g., plasmids) that does not integrate into the host-cell chromosome. The term transformation is used to denote the genetic alteration of a cell caused by the uptake and expression of foreign DNA regardless of the mechanism involved. (Note that transformation has a second meaning defined in Chapter 6, namely, the process by which normal cells with a finite life span in culture are converted into continuously growing cells similar to cancer cells.)

The phenomenon of transformation permits plasmid vectors to be introduced into and expressed by E.coli cells. In order to be useful in DNA cloning, however, a plasmid vector must contain a selectable gene, most commonly a drug-resistance gene encoding an enzyme that inactivates a specific antibiotic. As we've seen, the ampicillinresistance gene $\left(a m p^{r}\right)$ encodes $\beta$-lactamase, which inactivates the antibiotic ampicillin. After plasmid vectors are incubated with $E$. coli, those cells that take up the plasmid can be easily selected from the larger number of cells that do not by growing them in an ampicillin-containing medium. The ability to select transformed cells is critical to DNA cloning by plasmid vector technology because the transformation of E.coli with isolated plasmid DNA is inefficient. ${ }^{(6)}$ 
Normal E. coli cells cannot take up plasmid DNA from the medium. Exposure of cells to high concentrations of certain divalent cations, however, makes a small fraction of cells permeable to foreign DNA by a mechanism that is not understood. In a typical procedure, $E$. coli cells are treated with $\mathrm{CaCl}_{2}$ and mixed with plasmid vectors; commonly, only 1 cell in about 10,000 or more cells becomes competent to take up the foreign DNA. Each competent cell incorporates a single plasmid DNA molecule, which carries an antibiotic-resistance gene. When the treated cells are plated on a petri dish of nutrient agar containing the antibiotic, only the rare transformed cells containing the antibiotic-resistance gene on the plasmid vector will survive. All the plasmids in such a colony of selected transformed cells are descended from the single plasmid taken up by the cell that established the colony.

\section{Plasmid Cloning Permits Isolation of DNA Fragments from Complex Mixtures:-}

A DNA fragment of a few base pairs up to $\approx 20 \mathrm{~kb}$ can be inserted into a plasmid vector. When such a recombinant plasmid transforms an E.coli cell, all the antibiotic-resistant progeny cells that arise from the initial transformed cell will contain plasmids with the same inserted sequence of DNA. The inserted DNA is replicated along with the rest of the plasmid DNA and segregates to daughter cells as the colony grows. In this way, the initial fragment of DNA is replicated in the colony of cells into a large number of identical copies. Since all the cells in a colony arise from a single transformed parental cell, they constitute a clone of cells. The initial fragment of DNA inserted into the parental plasmid is referred to as cloned $D N A$, since it can be isolated from the clone of cells. ${ }^{(5,6)}$

\section{General procedure for cloning a DNA fragment in a plasmid vector:-}

Although not indicated by color, the plasmid contains a replication origin and ampicillin-resistance gene. Uptake DNA cloning allows fragments of DNA with a particular nucleotide sequence to be isolated from a complex mixture of fragments with many different sequences. As a simple example, assume you have a solution containing four different types of DNA fragments, each with a unique sequence. Each fragment type is individually inserted into a plasmid vector. The resulting mixture of recombinant plasmids is incubated with E.coli cells under conditions that facilitate transformation; the cells then are cultured on antibiotic selective plates. Since each colony that develops arose from a single cell that took up a single plasmid, all the cells in a colony harbor the identical type of plasmid characterized by the DNA fragment inserted into it. As a result, copies of the DNA fragments in the initial mixture are isolated from one another in the separate bacterial colonies. DNA cloning thus is a powerful, yet simple method for purifying a particular DNA fragment from a complex mixture of fragments and producing large numbers of the fragment of interest. ${ }^{(6)}$

\section{Restriction Enzymes Cut DNA Molecules at Specific Sequences;-}

To clone specific DNA fragments in a plasmid vector, as just described, or in other vectors discussed in later sections, the fragments must be produced and then inserted into the vector DNA. As noted in the introduction, restriction enzymes and DNA ligases are utilized to produce such recombinant DNA molecules.

Restriction enzymes are bacterial enzymes that recognize specific 4- to 8-bp sequences, called restriction sites, and then cleave both DNA strands at this site. Since these enzymes cleave DNA within the molecule, they are also called restriction endonucleases to distinguish them from exonucleases, which digest nucleic acids from an end. Many restriction sites, like the EcoRI site are short inverted repeat sequences; that is, the restriction-site sequence is the same on each DNA strand when read in the $5^{\prime} \rightarrow 3^{\prime}$ direction. Because the DNA isolated from an individual organism has a specific sequence, restriction enzymes cut the DNA into a reproducible set of fragments called restriction fragments Restriction-recognition sites are short DNA sequences recognized and cleaved by various restriction endonucleases. ${ }^{(8,9)}$

The word restriction in the name of these enzymes refers to their function in the bacteria from which they are isolated: a restriction endonuclease destroys (restricts) incoming foreign DNA (e.g., bacteriophage DNA or DNA taken up during transformation) by cleaving it at all the restriction sites in the DNA. Another enzyme, called modifying enzyme, protects a bacterium's own DNA from cleavage by modifying it at or near each potential cleavage site. The modification enzyme adds a methyl group to one or two bases, usually within the restriction site. When a methyl group is present there, the restriction endonuclease is prevented from cutting the DNA. Together with the restriction endonuclease, the methylating enzyme forms a restriction-modification system that protects the host DNA while it destroys foreign DNA. Restriction enzymes have been purified from several hundred different species of bacteria, allowing DNA molecules to be cut at a large number of different sequences corresponding to the recognition sites of these enzymes. 


\section{Restriction Fragments with Complementary "Sticky Ends" Are Ligated Easily:-}

EcoRI makes staggered cuts in the two DNA strands. Many other restriction enzymes make similar cuts, generating fragments that have a single-stranded "tail" at both ends. The tails on the fragments generated at a given restriction site are complementary to those on all other fragments generated by the same restriction enzyme. At room temperature, these single-stranded regions, often called "sticky ends," can transiently base-pair with those on other DNA fragments generated with the same restriction enzyme, regardless of the source of the DNA. This base pairing of sticky ends permits DNA from widely differing species to be ligated, forming chimeric molecules. During in vivo DNA replication, DNA ligase catalyzes formation of $3^{\prime} \rightarrow 5^{\prime}$ phosphodiester bonds between the short fragments of the discontinuously synthesized DNA strand at a replication fork. In recombinant DNA technology, purified DNA ligase is used to covalently join the ends of restriction fragments in vitro. This enzyme can catalyze the formation of a $3^{\prime} \rightarrow 5^{\prime}$ phosphodiester bond between the $3^{\prime}$-hydroxyl end of one restriction-fragment strand and the 5'-phosphate end of another restriction-fragment strand during the time that the sticky ends are transiently basepaired. When DNA ligase and ATP are added to a solution containing restriction fragments with sticky ends, the restriction fragments are covalently ligated together through the standard $3^{\prime} \rightarrow 5^{\prime}$ phosphodiester bonds of DNA. ${ }^{(10,11)}$

Some restriction enzymes, such as $A l u \mathrm{I}$ and $S m a \mathrm{I}$, cleave both DNA strands at the same point within the recognition site. These restriction enzymes generate DNA restriction fragments with "blunt" (flush) ends in which all the nucleotides at the fragment ends are base-paired to nucleotides in the complementary strand. In addition to ligating complementary sticky ends, the DNA ligase from bacteriophage T4 can ligate any two blunt DNA ends. However, blunt-end ligation requires a higher DNA concentration than ligation of sticky ends.

\section{Polylinkers Facilitate Insertion of Restriction Fragments into Plasmid Vectors:-}

Restriction enzymes to create fragments with sticky ends and DNA ligase to covalently link them allow foreign DNA to be inserted into plasmid vectors in vitro in a straightforward procedure. E.coli plasmid vectors can be constructed with a polylinker, a synthetic multiple-cloning-site sequence that contains one copy of several different restriction sites. When such a vector is treated with a restriction enzyme that recognizes a recognition sequence in the polylinker, it is cut at that sequence, generating sticky ends. In the presence of DNA ligase, DNA fragments produced with the same restriction enzyme will be inserted into the plasmid. The ratio of DNA fragments to be inserted to cut vectors and other reaction conditions are chosen to maximize the insertion of one restriction fragment per plasmid vector. The recombinant plasmids produced in vitro ligation reactions then can be used to transform antibiotic-sensitive $E$. coli cells as shown in. All the cells in each antibiotic-resistant clone that remains after selection contain plasmids with the same inserted DNA fragment, but different clones carry different fragments. $^{(12)}$

\section{Small DNA Molecules Can Be Chemically Synthesized:-}

Advances in synthetic chemistry now permit the chemical synthesis of single-stranded DNA (ssDNA) molecules of any sequence up to about 100 nucleotides in length. Synthetic DNA has a number of applications in recombinant DNA technology. Complementary ssDNAs can be synthesized and hybridized to each other to form a dsDNA with sticky ends. Such completely synthetic dsDNAs can be cloned into plasmid vectors just as DNA restriction fragments prepared from living organisms are. For example, the 57-bp polylinker sequence was chemically synthesized and then inserted into plasmid vectors to facilitate the cloning of fragments generated by different restriction enzymes. This example illustrates the use of synthetic DNAs to add convenient restriction sites where they otherwise do not occur. As described later in the chapter, synthetic DNAs are used in sequencing DNA and as probes to identify clones of interest. Synthetic DNAs also can be substituted for natural DNA sequences in cloned DNA to study the effects of specific mutations. Note that chains grow in the $3^{\prime} \rightarrow 5^{\prime}$ direction, opposite to the direction of DNA chain growth catalyzed by DNA polymerases. Once the chemistry for producing synthetic DNA was standardized, automated instruments were developed that allow researchers to program the synthesis of oligonucleotides of specific sequences up to about 100 nucleotides long. ${ }^{(13,14)}$

\section{PUC18:-}

It is a derivative of pBR322 and is much smaller $(-2.7 \mathrm{~kb})$ it has all the essential parts of pBR322, e.g., ampicillin resistance gene and Col E1 origin. The second scrobale marker is due to $E$. coli gene lacZ $\alpha$ encoding the fragment of $\beta$ galactosidase, the enzyme that hydrolyses lactose. from their lacZ genes. When pUC enters such an E.coli cell, the host genome and the plasmid encode for different parts of the p-galactosidase enzyme, which interact with each other to produce the active enzyme enabling these cells to hydrolyse lactose. $\beta$-galactosidase also hydrolyses X-gal 
(5-Bromo-4-chloro-3-indolyl-p-D-galactoside) to yield a blue dye. Therefore appropriate lacZ- E. coli cells transformed by the pUC vectors behave as lacZ+ and produce blue coloured colonies on a X-gal containing medium. ${ }^{(13,14)}$

A poly linker sequence located within the lacZ $\alpha$ provides several (10 in case of pUC18/pUC19) unique restriction sites for DNAinsertion. The unique restriction sites used for integration of DNA inserts into pUC vectors interrupt the lacZ $\alpha$ fragment so that appropriate $E$. coli cells possessing recombinant pUC DNA are $\beta$-galactosidase deficient and, as a result, produce white colonies on X-gal medium. Therefore, appropriate E.coli cells transformed with pUC recombinant DNA are grown on ampicillin, X-gal and IPG (isopropyl- $\beta$ D-thiogalactoside; it serves as inducer of $\beta$-galactosidase, while X-gal itself can not) containing medium to eliminate non transformed cells.

The white colonies are selected as they contain the recombinant DNA (in contrast, blue colonies will contain the unaltered vector). The other vectors in pUC series are pUC 8, pUC 9, pUC 12, pUC 13, etc. The pUC series vectors offer the following adantages over.

Gene informations :-

Gene source Bacillus subtilis 168

Gene description Secreted alkaliphilic lipase

NCBI Gene ID 938389

Gene length 639 bp

Gene product length 212 amino acid

\section{Application Of Gene Cloning:-}

Medical Purposes:-

Research for biotransplantation:-

Organs of animals can be transplanted to humans temporarily in case of the shortage of human organs. Cloning allows sufficient research on biotransplantation. ${ }^{(15)}$

Therapeutic cloning of stem cells from human embryos:-

Stem cells are building blocks for all human tissue. The most versatile cells are derived from embryos, usually obtained after they are discarded. In this process, scientists create embryos that are identical to people to obtain cells that van be used as exact tissue matches for them to work for cures to various cancers, hepatitis and other diseases.

\section{Clone for laboratory:-}

We could clone a series of laboratory mouse which are genetically identical. In doing this, we could use the mouse to test gene-therapy or medicines to see the effects of them on living beings, and can be sure that the effect that has taken place is due to the therapy, and not genetic differences of the mouse. ${ }^{(16)}$

\section{Agricultural applications:-}

Genetically modified cattle for specific purpose:-

Cloning could result in the mass production of genetically modified cattle that secret valuable drug into their milk.

Transgenic animals (animals engineered to carry genes from species other than their own) can be made to produce a wide variety of proteins that could be sold as drugs or proteins. Cloning can make creation of transgenic animals to be mass-produced. Large numbers of transgenic animals could produce vast quantities of needed drugs and other useful substances more efficiently and at a much lower cost.

An especially useful characteristic of plants for transgenic studies is the ability of cultured plant cells to give rise to mature plants. Meristematic (growing) cells from dissected plant tissue or cells within excised parts of a plant will grow in culture to form callus tissue, an undifferentiated lump of cells. Under the influence of plant growth hormones, different plant parts (roots, stems, and leaves) develop from the callus and eventually grow into whole, fertile plants. When an agrobacterium containing a recombinant Ti plasmid infects a cultured plant cell, the newly incorporated foreign gene is carried into the plant genome. ${ }^{(16,17)}$

As noted above A.tumefaciens readily infects dicots (petunia, tobacco, carrot) but not monocots; reliable techniques for introducing genes into monocots are still being developed. Direct introduction of DNA by electroporation has been successful in rice plants, which are monocots, and the future looks bright for the manipulation of other 
commercially important monocotyledonous crop plants. Also available for gene-transfer experiments are cells of a tiny, rapidly growing member of the mustard family called Arabidopsis thaliana. This plant is well-suited to genetic analysis of a variety of developmental and physiological processes. It takes up little space, is easy to grow, and has a small genome, and genes defined by mutations can be cloned by positional cloning strategies.

\section{Bacillus Subtilis:- Cell structure and metabolism:-}

Bacillus subtilis are rod-shaped bacteria that are Gram-positive (Perez 2000). The cell wall is a rigid structure outside the cell. It is composed of peptidoglycan, which is a polymer of sugars and amino acids. The peptidoglycan that is found in bacteria is known as murein. Other constituents that extend from the murein are teichoic acids, lipoteichoic acids, and proteins. The cell wall forms the barrier between the environment and the bacterial cell. It is also responsible for maintaining the shape of the cell and withstanding the cell's high internal turgor pressure (Schaechter 2006).

B.subtilis is capable of butanediol fermentation.It does not hydrolyze phospholipids nor casein; it does hydrolyze triglycerides. It produces citrate permease and cytochrome c. Bacillus subtilis is a model organism for studying endospore formation in bacteria. Endospores in Bacillus subtilis bacteria are mostly formed in the tips of protuberances extending downward from liquid surface pellicles (Schaechter 2006). Many strains produce spores with brown pigments. Depletion of carbon, nitrogen, or phosphorous causes the process of sporulation to begin, however, the process needs to start before the entire exhaustion of nutrients (Perez 2000). Otherwise, the spore formation cannot be completed due to the fact that the nutrients are too low for the energy-requiring sporulation process. This allows the cells to avoid being stuck in a vulnerable position.

The formation of the endospore occurs in several stages, denoted 0 through VI. Sporulation occurs in the following fashion. First the nucleoid lengthens, becoming an axial filament. Then, the cell forms a polar septum, one-fourth of the cell length from one end, and begins to divide. The smaller product of this division is called the forespore and the larger product is called the mother cell (Perez 2000). The mother cell is responsible for nourishing the newly formed spore. When the septum forms, $30 \%$ of the chromosome is already on the forespore side (Schaechter 2006). The remaining $70 \%$ of the chromosome enters the forespore in a fashion similar to DNA transfer during conjugation; it is pumped by a protein called SpoIIIE. The mother cell then engulfs the forespore by acting like a phagocyte. This causes the forespore to have two cytoplasmic membranes with a thick murein layer, namely the cortex, between them. A protein spore coat and an exosporium, a membranous layer, form outside of the forespore membranes. At this time, the forespore undergoes internal changes. Lastly, the forespore leaves the mother cell upon lysis of the mother cell (Perez 2000). A mature endospore has no metabolic activity; it is inert. The interior of the endospore, the core, is very dry and resistant to moisture (Schaechter 2006).

\section{Genome structure:-}

Only one DNA molecule is present in these cells. Bacillus subtilis has one circular chromosome. The total size of all the DNA is 4,214,814 bp (4.2 Mbp) (TIGR CMR). 4,100 genes code for proteins. 53\% of the protein-coding genes are only seen once, while $25 \%$ of the genome relates to families of genes that have undergone gene duplication (Kunst 1997).

A great portion of the genome corresponds to carbon source applications (Kunst 1997). 192 of the 4,100 genes are considered indispensable, and an additional 79 are thought to be essential. Most of the essential genes are involved in metabolism. Half of the essential genes are responsible for processing information, one-fifth of them are responsible for cell wall synthesis, cell division and shape, and one-tenth of them were responsible for the energetics of the cell. The essential genes that code for functions that are not known are 4\% (Kobayashi 2003).Bacillus subtilis bacteria are capable of secreting antibiotics in great numbers to the exterior of the cell (Ara 2007). Five signal peptidase genes were found to be important for this secretion function. Many of Bacillus subtilis cells' genes are responsible for antibiotic synthesis. ${ }^{(17)}$

\section{Materials and Methods:-}

Isolation Of Genomic Dna From Bacteria By 


\section{Phenol-Chloroform Method:-}

The isolation of DNA from bacteria is a relatively simple process. The organism should be grown in favorable medium at optimum temperature and should be harvested in late log to early stationary phase for maximum yield. The lysis of bacteria is initiated by resuspending the bacterial pellet in lysis buffer. The role of lysis buffer in cell disruption and isolation of DNA is as follows

Tris HCl: Buffering agent used to maintain a constant $\mathrm{pH}$ for isolating DNA.

EDTA: Acts as a chelating agent that removes divalent cations necessary for DNase activity.

SDS: Anionic detergent disrupts cell membrane and lipid molecules and also reduces DNase activity by denaturing DNase.

\section{Sodium Chloride:-}

Ruptures the cell and denatures DNA into single stranded.

The lysate is treated with Chloroform: Isoamyl alcohol which act as defoaming agent and are commonly dissociate nucleic acid. Sodium acetate forms precipitate with SDS along with cellular debris. To washout the remaining chilled ethanol is added to precipitate DNA(if the ionic strength of solution is high) and the isolated DNA is dissolved in TE buffer at $4^{\circ} \mathrm{C}$.

\section{Requirements:-}

1. LB Broth

2. Bacillus subtilis 168 culture

3. Lysis buffer: $10 \mathrm{mM}$ Tris $\mathrm{HCl}, 5 \mathrm{mM}$ EDTA, $0.5 \%$ SDS, $1 \mathrm{M} \mathrm{NaCl}$

4. Phenol: chloroform mixture in the ratio $1: 1$

5. Chloroform: Isoamyl alcohol mixture in the ratio $24: 1$

6. 3M sodium acetate

7. TE buffer: $10 \mathrm{mM}$ Tris, $1 \mathrm{mM}$ EDTA

\section{Procedure:-}

1. Take $2 \mathrm{ml}$ of Bacillus subtilis 168 culture broth in an eppendroff tube.

2. Collect the pellet and discard the supernatant.

3. Resuspend the pellet in $1 \mathrm{ml}$ of lysis buffer.

4. Incubate at $45^{\circ} \mathrm{C}$ in boiling water bath for $10 \mathrm{~min}$.

5. Add $1 \mathrm{ml}$ of phenol: chloroform mixture (1:1 ratio) and centrifuge at 10,000 rpm for 10 minutes.

6. Transfer the upper aqueous layer and add equal volume of chloroform: Isoamyl alcohol mixture (24:1 ratio) and add $1 / 20^{\text {th }}$ volume of $3 \mathrm{M}$ sodium acetate.

7. Centrifuge at $10,000 \mathrm{rpm}$ for 10 minutes.

8. Transfer the upper aqueous layer to a new tube and add double the volume of chilled ethanol and incubate at $20^{\circ} \mathrm{C}$ for 20 minutes or $4^{\circ} \mathrm{C}$ overnight.

9. Centrifuge at $12,000 \mathrm{rpm}$ for 10 minutes .

10. Discard the supernatant and airdry the pellet.

11. Dissolve the DNA pellet in 20-50 $\mu$ l of TE buffer.

12. Store at $4^{\circ} \mathrm{C}$.

\section{Agarose Gel Electrophoresis Of Genomic Dna:-}

\section{Procedure:-}

The technique consists of 3 basic steps:

Preparation of Agarose gel.

Electrophoresis of DNA fragments

Visualization of DNA fragments.

\section{Requirements:-}

1. -Agarose

2. -TAE buffer 


\section{Preparation of 1\% Agarose Gel:-}

1. Prepare $1 \mathrm{X}$ electrophoresis buffer for both gel and electrophoresis.

2. Weigh an appropriate amount of agarose to the appropriate volume of $1 \mathrm{X}$ electrophoresis buffer in a conical flask (1\% for normal DNA isolation, $1.5 \%$ for PCR product).

3. Heat in a microwave or boiling water bath, rotate the flask occasionally, until the agarose is dissolved.

4. Cool the agarose to $55-60^{\circ} \mathrm{C}$ using running tap water.

5. Insert the comb before pouring the gel on to the gel tray.

6. Pour the agarose solution on to the gel tray .and add sufficient amount of $1.5 \mathrm{ul}$ Ethidium bromide.

7. Leave the gel to solidify for $30-40$ minutes.

8. Carefully remove the comb .

9. Fill the electrophoresis tank containing the gel with $1 \mathrm{X}$ electrophoresis buffer.(Add enough buffers to cover the gel with $1 \mathrm{~mm}$ liquid above the surface of the gel. If too much buffer is used the electric current will pass through the buffer instead of the gel)

\section{Electrophoresis of DNA:-}

1. Add DNA and gel loading buffer in 6: 4 ratio.

2. Apply DNA to the wells formed in the gel.

3. Connect the electrodes and apply the current (1-10 volts/ $\mathrm{cm}$ of the gel) until the dye has migrated an appropriate distance in the gel.

4. Connect the power cord to the electrophoretic power supply and load the sample in the wells in the desired order.

5. Set the voltage to $50 \mathrm{~V}$ and current to $75 \mathrm{~mA}$ and switch on power supply.

6. After 20 minutes increase the voltage to 100 and run for 20 minutes.

\section{Visualization of DNA fragments:-}

After DNA has run up to $80 \%$ of the gel, location of bands is determined by examining the gel under UV trans illuminator

\section{Nanospectrophotometer:-}

Procedure:-

1. Turn on the computer and log in. Open NanoDrop software; link is on desktop.

2. Choose the type of measurement you'd like to make* (Nucleic Acid, UV-Vis, Cell cultures, -rotein, etc.)

3. A window opens asking you to load a water sample to initiate the machine: add $1.5 \mathrm{ul}$ of millipore-filtered water to pedestal and lower the arm. Click "proceed".

4. When finished, clean top and bottom measurement pedestal surfaces with a clean tissue paper.

5. Load $1.5 \mu \mathrm{L}$ water or other appropriate blank (eg. TE buffer) on the pedestal and lower the top arm. Click on the "BLANK" button to run the blank measurement.

6. When finished, clean the pedestal (top and bottom) with a tissue paper.

7. Load a $1.5 \mu \mathrm{L}$ of DNA on the lower pedestal, lower the arm. If desired, enter the sample name in the window provided.

8. Click the "Measure" button- the display will then show the spectrum and show the calculated concentration.

9. When finished, click "show report". From here you can save or print the report. The data can be saved to your own folder, P: drive, or disc.

Clean the pedestal and leave the arm down. Exit software.

\section{PCR (POLYMERASE CHAIN REACTION):-}

\section{Basic reaction:-}

Denaturation:-

Heating separates the double stranded DNA

\section{Renaturation:-}

Slow cooling anneals the two strands 


\section{Extension:-}

Polymerisation of two strands by Taq polymerase using dNTP

Each DNA polymerase works best under optimal temperature, $\mathrm{pH}$ and salt concentration PCR buffer provides optimal $\mathrm{pH}$ and salt condition

\section{Amplification Of Lipase Gene By Hot Start Pcr Method:-}

1. PCR is used to amplify specific regions of a DNA strand (the DNA target). This can be a single gene, a part of a gene, or a non-coding sequence. We amplified DNA fragments (Lipase Gene) by HOT START PCR METHOD .

2. A basic PCR set up requires several components and reagents. These components include:

3. DNA template that contains the DNA region (target) to be amplified.

4. Two primers, which are complementary to the DNA regions at the 5' (five prime) or 3' (three prime) ends of the

5. DNA region.

6. Taq polymerase or another DNA polymerase with a temperature optimum at around $70^{\circ} \mathrm{C}$.

7. Deoxynucleoside triphosphates (dNTPs; also very commonly and erroneously called deoxynucleotide triphosphates), the building blocks from which the DNA polymerases synthesizes a new DNA strand.

8. Buffer solution, providing a suitable chemical environment for optimum activity and stability of the DNA polymerase.

9. Divalent cations, magnesium or manganese ions; generally $\mathrm{Mg}^{2+}$ is used, but $\mathrm{Mn}^{2+}$ can be utilized for PCRmediated DNA mutagenesis, as higher $\mathrm{Mn}^{2+}$ concentration increases the error rate during DNA synthesis

10. Monovalent cation potassium ions.

\begin{tabular}{|c|c|c|}
\hline Components (Stock conc.) & Final conc. & Volume \\
\hline $10 \mathrm{X}$ assay buffer & $1 \mathrm{X}$ & $5 \mu \mathrm{l}$ \\
\hline $10 \mathrm{mM}$ dNTP's & $10 \mathrm{mM}$ & $1 \mu \mathrm{l}$ \\
\hline Taq polymerase $(3 \mathrm{U} / \mu \mathrm{l})$ & $3 \mathrm{U} / \mu \mathrm{l}$ & $1 \mu \mathrm{l}$ \\
\hline Forward Primer $(490 \mathrm{pm} / \mu \mathrm{l})$ & $10 \mathrm{pm} / \mu \mathrm{l}$ & $1 \mu \mathrm{l}$ \\
\hline Reverse Primer $(560 \mathrm{pm} / \mu \mathrm{l})$ & $10 \mathrm{pm} / \mu \mathrm{l}$ & $1 \mu \mathrm{l}$ \\
\hline DNA & $100 \mathrm{ng} / \mu \mathrm{l}$ & $1 \mu \mathrm{l}$ \\
\hline Sterile Distilled water & - & $40 \mu \mathrm{l}$ \\
\hline Total Volume & & $\mathbf{5 0 \mu l}$ \\
\hline
\end{tabular}

\section{Requirements:-}

1. Template DNA

2. dNTP's

3. $\mathrm{Mgcl}_{2}$

4. Taq polymerase

5. Primers

6. 10x Assay buffer

\begin{tabular}{|c|c|c|c|c|c|c|c|c|c|c|c|}
\hline$\underline{\underline{N}}$ & $\begin{array}{l}\text { Oil } \\
\text { go } \\
\text { na } \\
\text { me }\end{array}$ & Sequence(5->3) & $\begin{array}{l}\text { yie } \\
\text { ld } \\
\{O \\
D\}\end{array}$ & $\begin{array}{l}\text { yi } \\
\text { el } \\
\text { d } \\
\{ \\
\mu \mathrm{g} \\
\}\end{array}$ & $\begin{array}{l}\text { yiel } \\
\mathrm{d} \\
\{\mathrm{nm} \\
\mathrm{ol}\} \\
\}\end{array}$ & $\begin{array}{l}\text { Vol.f } \\
\text { o } \\
100 p \\
\text { mol/ } \\
\mu \mathrm{l}\end{array}$ & $\begin{array}{l}\mathrm{T} \\
\mathrm{M} \\
\left\{\begin{array}{l}\mathrm{o} \\
\mathrm{C}\}\end{array}\right.\end{array}$ & $\begin{array}{l}\text { MW } \\
\{\mathrm{g} / \\
\text { mol } \\
\}\end{array}$ & $\begin{array}{l}\text { GC- } \\
\text { com } \\
\text { tent }\end{array}$ & $\begin{array}{l}\text { Synth } \\
\text { esis } \\
\text { scale }\end{array}$ & $\begin{array}{l}\text { purific } \\
\text { ation }\end{array}$ \\
\hline 1 & $\begin{array}{l}\text { est } \\
\text { A- } \\
\text { FP }\end{array}$ & $\begin{array}{l}\text { CCTAGGATGAAATTTGTA } \\
\text { AAAAGAGGG(27) }\end{array}$ & $\begin{array}{l}19 . \\
1\end{array}$ & $\begin{array}{l}48 \\
3\end{array}$ & 57.3 & 573 & $\begin{array}{l}60 . \\
4\end{array}$ & $\begin{array}{l}842 \\
0\end{array}$ & $37 \%$ & $\begin{array}{l}0.01 \mu \\
\text { mol }\end{array}$ & HPSF \\
\hline & est & CTTAAGTTAATTCGTATTC & & & & & & & & & \\
\hline
\end{tabular}




\begin{tabular}{|c|c|c|c|c|c|c|c|c|c|c|c|}
\hline 2 & $\begin{array}{l}\text { A- } \\
\text { RP }\end{array}$ & AGGCCCC(26) & $\begin{array}{l}26 . \\
6\end{array}$ & $\begin{array}{l}76 \\
5\end{array}$ & 96.6 & 969 & $\begin{array}{l}61 . \\
6\end{array}$ & $\begin{array}{l}789 \\
6\end{array}$ & $\begin{array}{l}42.3 \\
\%\end{array}$ & $\begin{array}{l}0.01 \mu \\
\text { mol }\end{array}$ & HPSF \\
\hline
\end{tabular}

Nuclease free water

\begin{tabular}{|c|c|c|c|}
\hline Cycle no. & Temp & time & Repeats \\
\hline 1 & $95^{\circ} \mathrm{C}$ & $3 \min$ & 1 \\
\hline \multirow[t]{3}{*}{2} & $95^{\circ} \mathrm{C}$ & $30 \mathrm{sec}$ & \\
\hline & $58^{\circ} \mathrm{C}$ & 30 & \multirow[t]{2}{*}{5} \\
\hline & $72^{\circ} \mathrm{C}$ & 1 & \\
\hline \multirow[t]{3}{*}{3} & $95^{\circ} \mathrm{C}$ & 30 & \multirow[t]{3}{*}{5} \\
\hline & $57^{\circ} \mathrm{C}$ & 30 & \\
\hline & $72^{\circ} \mathrm{C}$ & 1 & \\
\hline \multirow[t]{3}{*}{4} & $95^{\circ} \mathrm{C}$ & 30 & \multirow[t]{3}{*}{15} \\
\hline & $56^{\circ} \mathrm{C}$ & 30 & \\
\hline & $72^{\circ} \mathrm{C}$ & 1 & \\
\hline \multirow[t]{3}{*}{5} & $95^{\circ} \mathrm{C}$ & 30 & \multirow[t]{3}{*}{5} \\
\hline & $55^{\circ} \mathrm{C}$ & 30 & \\
\hline & $72^{\circ} \mathrm{C}$ & 1 & \\
\hline 6 & $72^{\circ} \mathrm{C}$ & 2 & 1 \\
\hline 7 & $4^{\circ} \mathrm{C}$ & & 1 \\
\hline
\end{tabular}

\section{Procedure:-}

-The PCR CYCLE consists of a near about 30 cycles; each cycle typically consists of 2-3 discrete temperature steps. Most commonly PCR is carried out with cycles that have three temperature steps The cycling is often preceded by a single temperature step (called hold) at a high temperature $\left(>95^{\circ} \mathrm{C}\right)$, and followed by one hold at the end for final product extension or brief storage. The temperatures used and the length of time they are applied in each cycle depend on a variety of parameters. These include the enzyme used for DNA synthesis, the concentration of divalent ions and dNTPs in the reaction, and the melting temperature ( $\underline{\mathrm{Tm}})$ of the primers.

-Initialization step: This step consists of heating the reaction to a temperature of $95^{\circ} \mathrm{C}$ which is held for 1 minute. It is only required for DNA polymerases that require heat activation by hot-start PCR.

-Denaturation step: This step is the first regular cycling event and consists of heating the reaction to $95^{\circ} \mathrm{C}$ for 30 seconds. It causes melting of DNA

-Template and primers by disrupting the hydrogen bonds between complementary bases of the DNA strands, yielding single strands of DNA.

-Annealing step: The reaction temperature is lowered to $56-59^{\circ} \mathrm{C}$ for 30 seconds allowing annealing of the primers to the single-stranded DNA template. Typically the annealing temperature is about 3-5 degrees Celsius below the $\mathrm{Tm}$ of the primers used. Stable DNA-DNA hydrogen bonds are only formed when the primer sequence very closely matches the template sequence. The polymerase binds to the primer-template hybrid and begins DNA synthesis.

-Extension/elongation step: The temperature at this step depends on the DNA polymerase used; Taq polymerase has its optimum activity temperature at $75-80^{\circ} \mathrm{C}$ and commonly a temperature of $72^{\circ} \mathrm{C}$ is used with this enzyme. At this step the DNA polymerase synthesizes a new DNA strand complementary to the DNA template strand by adding dNTP that are complementary to the template in 5' to $3^{\prime}$ direction, condensing the 5 '-phosphate group of the dNTPs with the 3'-hydroxyl group at the end of the nascent (extending) DNA strand. The extension time depends both on the DNA polymerase used and on the length of the DNA fragment to be amplified. As a rule-of-thumb, at its optimum temperature, the DNA polymerase will polymerize a thousand bases per minute. Under optimum conditions, i.e., if there are no limitations due to limiting substrates or reagents, at each extension step, the amount of DNA target is doubled, leading to exponential (geometric) amplification of the specific DNA fragment. 
-Final elongation: This single step is occasionally performed at a temperature of $70-74^{\circ} \mathrm{C}$ for $5-15$ minutes after the last PCR cycle to ensure that any remaining single-stranded DNA is fully extended.

-Final hold: This step at $4-15^{\circ} \mathrm{C}$ for an indefinite time may be employed for short-term storage of the reaction.

\section{Confirmation Of Pcr Product By Agarose Gel Electrophoresis:-}

Requirements:-

1. Agarose

2. TAE buffer

\section{Preparation of 1\% Agarose Gel:-}

1. Prepare $1 \mathrm{X}$ electrophoresis buffer for both gel and electrophoresis.

2. Weigh an appropriate amount of agarose to the appropriate volume of $1 \mathrm{X}$ electrophoresis buffer in a conical flask (1\% for normal DNA isolation, $1.5 \%$ for PCR product)

3. Heat in an microwave or boiling water bath, rotate the flask occasionally, until the agarose is dissolved.

4. Cool the agarose to $55-60^{\circ} \mathrm{C}$ using running tap water.

5. Insert the comb before pouring the gel on to the gel tray.

6. Pour the agarose solution on to the gel tray and add sufficient amount of ethidium bromide.

7. Leave the gel to solidify for 30-40 min.

8. Carefully remove the comb

9. Fill the electrophoresis tank containing the gel with $1 \mathrm{X}$ electrophoresis buffer.

10. (Add enough buffers to cover the gel with $1 \mathrm{~mm}$ liquid above the surface of the gel. If too much buffer is used the electric current will pass through the buffer instead of the gel)

\section{Electrophoresis of DNA:-}

1. Add PCR product (DNA of Bacillus subtilis 168) and gel loading buffer in 6: 4 ratio

2. Apply samples to the wells formed in the gel.

3. Connect the electrodes and apply the current (1-10 volts/ $\mathrm{cm}$ of the gel) until the dye has migrated an appropriate distance in the gel.

4. Connect the power cord to the electrophoretic power supply and load the sample in the wells in the desired order.

5. Set the voltage to $50 \mathrm{~V}$ and current to $75 \mathrm{~mA}$ and switch on power supply.

6. After 20 minutes increase the voltage to 100 and run for 20 minutes.

\section{Visualization of DNA fragments:-}

After DNA has run upto $80 \%$ of the gel, location of bands is determined by examining the gel under UV transilluminator.

\section{ISOLATION OF PLASMID DNA (PUC 18) from the host:-}

1. Cell lysis

2. Removal of proteins and chromosomal DNA

3. Collection of plasmid DNA

4. Further purification if necessary

\section{Procedure:-}

Take $1 \mathrm{ml}$ culture in an eppendroff tube.

Spin in centrifuge at 10,000 rpm for 5 minutes.

Resuspend the cells; in $100 \mu 1$ of solution 1(ice cold) vortex gently.

Add $200 \mu \mathrm{l}$ of freshly prepared solution 2 . Close the tube gently and mix the contents evenly by inverting the tubes.

Add $150 \mu$ l of solution 3 , close the tubes tightly and mix the contents.

Spin in centrifuge at $10,000 \mathrm{rpm}$ for 10 minutes. 
Transfer the supernatant to a fresh $1.5 \mathrm{ml}$ tube and add $450 \mu \mathrm{l}$ of ethanol/Isopropanol to precipitate the DNA. Keep at room temperature for $10-15$ mins.

Spin in centrifuge at 10,000rpm for 10mins, decant the supernatant, stand the tube in inverted position on a paper to drain the fluid away.

Rinse the pellet with $500 \mu \mathrm{l}, 70 \%$ ethanol, and spin at 10,000rpm for 5 mins. Remove the supernatant as described in the above step, dry the pellet in air /10min till there is no trace of ethanol

Add $20 \mu \mathrm{l}$ of TE buffer so that DNA goes into the solution

Checking The Plasmid Dna On Agarose Gel Electrophoresis:-

Requirements:-

1. -Agarose

2. -TAE buffer

Preparation of 1\% Agarose Gel:-

1. *Prepare $1 \mathrm{X}$ electrophoresis buffer for both gel and electrophoresis.

2. *Weigh an appropriate amount of agarose to the appropriate volume of $1 \mathrm{X}$ electrophoresis buffer in a conical flask (1\% for normal DNA isolation, $1.5 \%$ for PCR product).

3. *Heat in a microwave or boiling water bath, rotate the flask occasionally, until the agarose is dissolved.

4. *Cool the agarose to $55-60^{\circ} \mathrm{C}$ using running tap water.

5. *Insert the comb before pouring the gel on to the gel tray.

6. *Pour the agarose solution on to the gel tray .and add sufficient amount of Ethidium bromide.

7. *Leave the gel to solidify for $30-40 \mathrm{~min}$.

8. *Carefully remove the comb

9. *Fill the electrophoresis tank containing the gel with $1 \mathrm{X}$ electrophoresis buffer.

10. (Add enough buffers to cover the gel with $1 \mathrm{~mm}$ liquid above the surface of the gel. If too much buffer is used the electric current will pass through the buffer instead of the gel)

\section{Electrophoresis of plasmid DNA:-}

1. *Add sample and gel loading buffer in $6: 4$ ratio

2. *Apply samples to the wells formed in the gel.

3. *Connect the electrodes and apply the current (1-10 volts/ $\mathrm{cm}$ of the gel) until the dye has migrated an appropriate distance in the gel.

4. *Connect the power cord to the electrophoretic power supply and load the sample in the wells in the desired order.

5. *Set the voltage to $50 \mathrm{~V}$ and current to $75 \mathrm{~mA}$ and switch on power supply.

6. *After 20 minutes increase the voltage to 100 and run for 20 minutes.

Visualization of Plasmid DNA fragments:-

After DNA has run up to $0.8 \%$ of the gel, location of bands is determined by examining the gel under UV transilluminator.

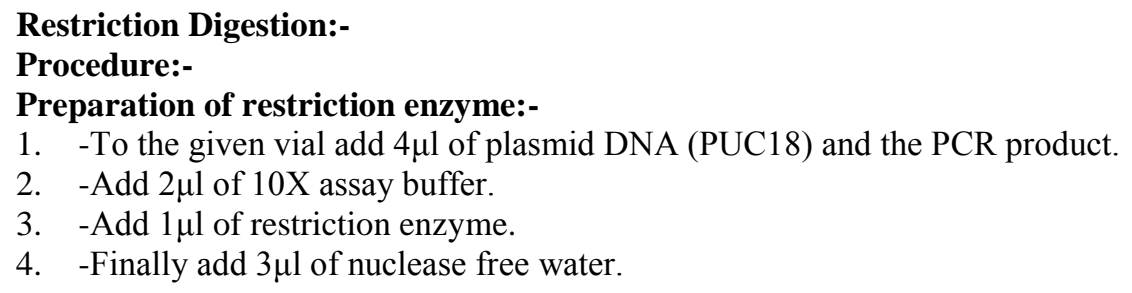

Incubation:-

Incubate the reaction mixture in $37^{\circ} \mathrm{C}$ dry bath for one hour. 
Arresting the reaction digestion:-

1. -Stop the reaction by cooling to $0^{\circ} \mathrm{C}$ and by adding $2 \mu$ of gel loading dye that acts as a stop solution.

2. -Incubate the stop reaction mixture for 10 minutes at $65^{\circ} \mathrm{C}$.

3. - Cool rapidly to $0^{\circ} \mathrm{C}$ by keeping the reaction mixture in ice.

Agarose gel electrophoresis:-

-Load the DNA digest onto $0.8 \%$ agarose gel and run at $50 \mathrm{~V}$ for 1 hour.

Visualizing restriction digestion:-

The band pattern digested DNA is observed by illumination of gel with UV light which causes Ethidium bromide stain fragment to fluorescence

Ligation:-

Procedure:-

Preparation of ligation mixture:-

To the $100 \mu 1$ of restricted sample plasmid DNA (PUC18) and the PCR product. add $1 \mu 1$ of ligase assay buffer and $1 \mu \mathrm{l}$ of $\mathrm{T}_{4}$ DNA ligase.

Incubation:-

Incubate the vial overnight at $16^{\circ} \mathrm{C}$

Arresting the reaction:-

After incubation, remove the vial and add $2 \mu 1$ of gel loading dye.

Agarose gel electrophoresis:-

Load the contents from the vial in which ligation were carried out into $0.8 \%$ of agarose gel, care should be taken while loading so that the contents are not spread out of the well.

Visualization of ligated sample:-

Ligation is observed by illumination of the gel with UV light. Which causes the Ethidium bromide stained DNA fragments to fluorescence.

\section{Preparation Of Competent Cells:-}

Procedure:-

1. -DH5 $\alpha$ strain into $5 \mathrm{ml}$ of LB broth and incubate at $37^{\circ} \mathrm{C}$ for $24 \mathrm{hrs}$.

2. - Transfer $5 \mathrm{ml}$ culture i.e., DH5 $\alpha$ into $100 \mathrm{ml} \mathrm{LB}$ medium and incubate at $37^{\circ} \mathrm{C}$ for 18 to $24 \mathrm{hrs}$ (till the O.D reach 0.2 to 0.6 at $600 \mathrm{~nm}$ ).

3. -After incubation quickly chill the culture on ice and leave on ice for 10 to $20 \mathrm{~min}$.

4. -Transfer the culture aseptically into centrifuge tubes and spin at $6000 \mathrm{rpm}$ for 10 to $20 \mathrm{~min}$.

5. -Discard the supernatant, to the pellet add $0.1 \mathrm{M} \mathrm{CaCl} 2$ (approximately $6 \%$ of the volume you spin).

6. -Suspend the cell pellet in $\mathrm{CaCl}_{2}$ this should be done by placing the tubes in ice buckets and leave it on ice for $30 \mathrm{~min}$.

7. -Centrifuge at $6000 \mathrm{rpm}$ for $8 \mathrm{~min}$.

8. -Discard supernatant and resuspend the cells gently in $\mathrm{CaCl}_{2}$ ( $0.8 \%$ of the volume you have spun).

9. -Aseptically transfer $10 \mu \mathrm{l}$ of the above competent cells into 5 eppendroff tube. All transferring should be done on ice.

Transformation:-

Procedure:-

1. -To the $100 \mu 1$ of the competent cell prepared, add $20 \mu 1$ of plasmid DNA (PUC18). Gently tap and keep the vial on ice for $20 \mathrm{~min}$.

2. -The competent cells are subjected to heat shock treatment at $42^{\circ} \mathrm{C}$ (on a water bath) for $2 \mathrm{~min}$.

3. -Remove the vials after heat shock and chill the vial on ice for $20 \mathrm{~min}$. 
4. -Add $1 \mathrm{ml}$ of $\mathrm{LB}$ broth aseptically to the vial and incubate the culture for 1 hour at $37^{\circ} \mathrm{C}$ to allow the bacteria to express and recover the antibiotic resistance.

5. -Prepare the LB plates containing $50 \mu \mathrm{g} / \mathrm{ml}$ ampicillin and inoculate the transformed cells onto the plates.

\section{Antibiotic Sensitivity Test:-}

Procedure:-

1. -Prepare $50 \mathrm{ml}$ of LB agar, autoclave.

2. -Divide equally to 3 plates mix $50 \mathrm{mg} / \mathrm{ml}$ antibiotics like ampicillin, tetracycline pour to plates.

3. -After solidification spread the transformed cells. Keep 1 plate without antibiotic as control.

\section{Blue White Colony Selection:-}

\section{Procedure:-}

1. -Spread the following on a LB (+appropriate antibiotic) plate (If you are going to plate 100ul of transformed cells): $100 \mathrm{ul}$ of $100 \mathrm{mM} \mathrm{IPTG}+40 \mathrm{ul}$ of X-gal $(20 \mathrm{mg} / \mathrm{ml})$.

2. -Perform transformation of ligation into the bacteria (note: make sure you are using the right host bacterial strain for the blue white selection, also see the background section below) and then spread them on the X-gal containing plates.

3. -After overnight incubation, store the plate in $4{ }^{0} \mathrm{C}$ for several hours. This allows the blue color to develop fully. Colonies that contain active $\beta$-galactosidase are pale blue in center and dense blue at their periphery. White colonies occassionally show a faint blue spot in the center, but these are colorless at the periphery.

\section{Result and Discussions:- \\ Bacterial Identification:-}

The strain of Baciilus subtilis 168 is ordered from the MTCC. To identify the bacterial species the gram positive test was conducted and successfully strain was identified as Baciillus species.

Isolation and PCR Cloning of the Thermostable estA Lipase Gene:-

A fragment of lipase gene 212 bp in size was obtained using a pair of highly degenerate primers (estA FP and estA RP). This lipase gene fragment showed the highest homology with the B. stearothermophilus P1 lipase gene at $99 \%$ homology. Primer estA FP and estA RP was designed based on the first 21 nucleotides of the ORF of B. subtilis 168 estA FP lipase gene sequence, whereas primer estA RP was from the last 21 nucleotides of the same sequence. Bacillus subtilis 168 has been successfully isolated and plated on agar plate. 

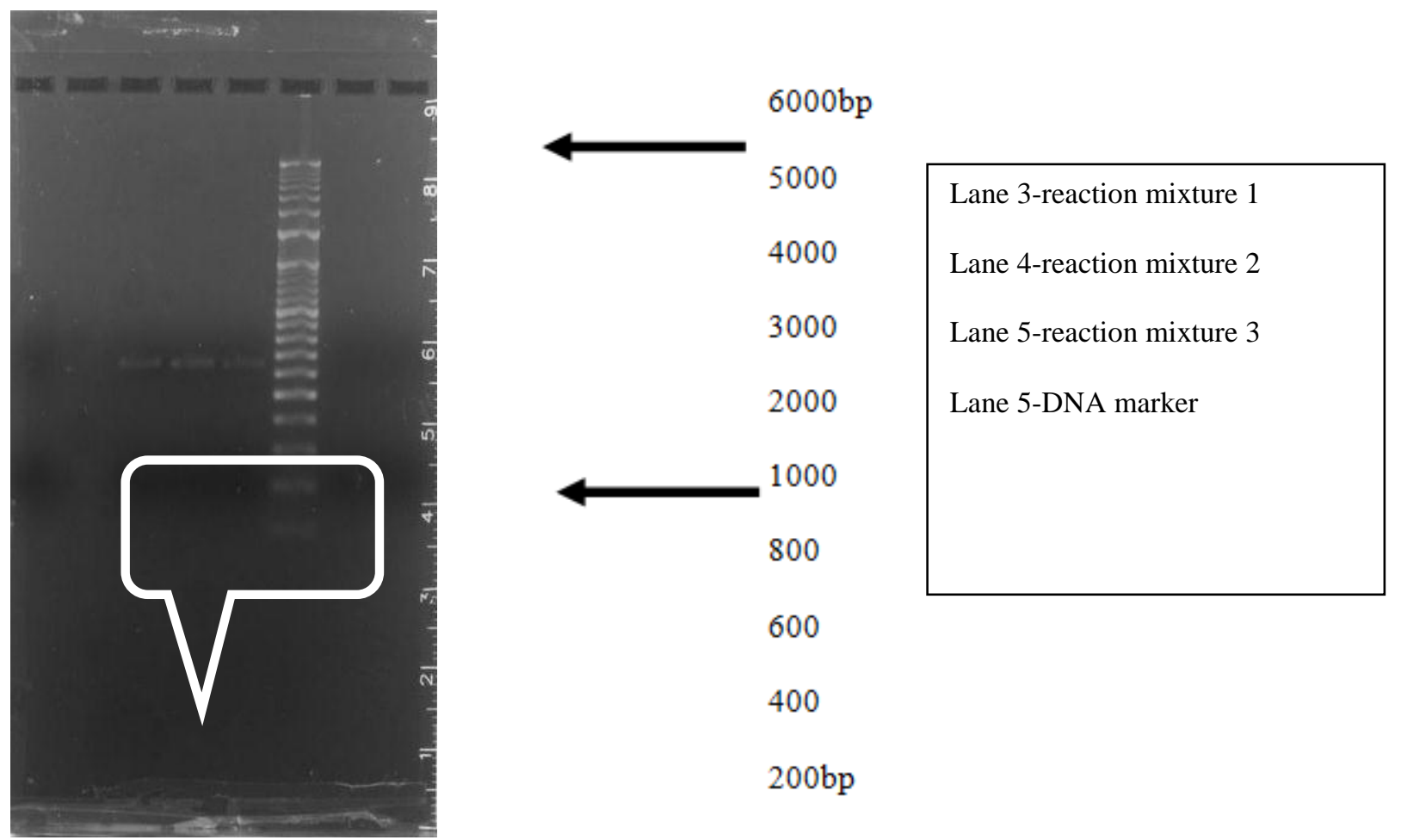

Figure:-PCR result for lipase Gene

Lane 3,4,5 show the lipase PCR band corresponding to marker DNA. PCR product of the lipase gene has been successfully amplified.

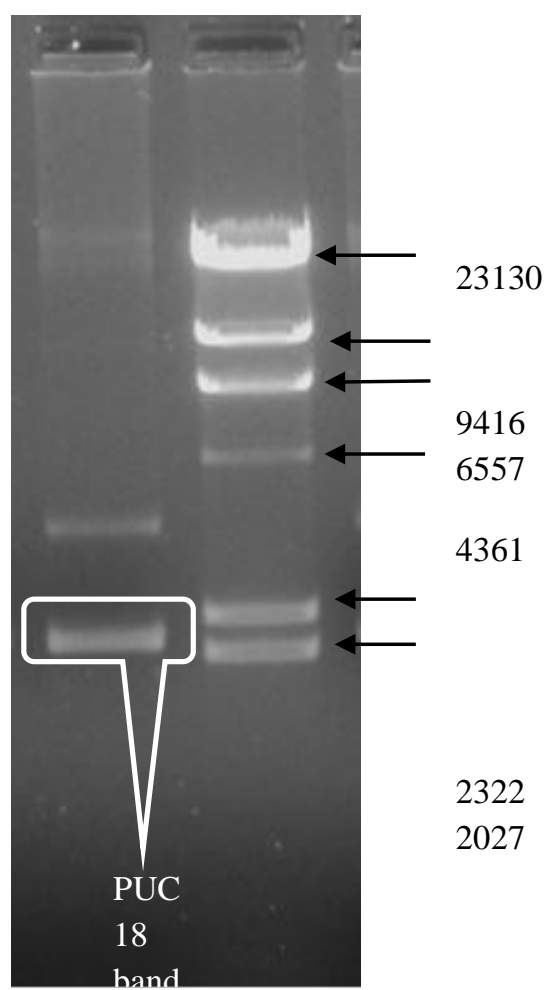

Lane 1 PUC18 plasmid

Lane $2 \lambda$ Hindlll digest DNA marker

Figure:-plasmid PUC 18 isolated from E.coli DH5 Alpha 
lane 1 shows PUC 18 plasmid successfully isolated from E. coli DH5 alpha.

The plasmid has been successfully isolated from E.coli DH5 $\alpha$ by alkaline lysis with SDS preparation.

\section{Restriction digestion:-}

The restriction digestion has been successfully completed by using restriction enzyme (BamHI) having sites on plasmid as well as on PCR fragments.

\section{Ligation:-}

The 1.14kbp of phytase per fragments successfully ligated with pUC18 plasmid at MCS site by using T4 DNA ligase enzyme.

\section{Competent cell preparation:-}

By using calcium chloride method $200 \mu 1$ of competent cells are prepared and stored at $-20^{\circ} \mathrm{C}$ for further use.

\section{Transformation:-}

Recombinant plasmid has been transformed into the host E.coli DH5 $\alpha$. blue colonies and white colonies on Agar plates show the non-transformed and transformed bacterial colonies respectively.

grown on $90 \mathrm{~mm}$ agar plates having both transformed and non-transformed colonies on plate. The colonies which is in white coloured corresponds to the recombinant bacterial colonies and colonies in blue colour are the nonrecombinant one.

By using X-GAL and antibiotic ampicillin, recombinant colonies are grown on $90 \mathrm{~mm}$ agar plates .The colonies which are in white colour correspond to the recombinant bacterial colonies and those in blue colour are corresponding to the non recombinant colonies.

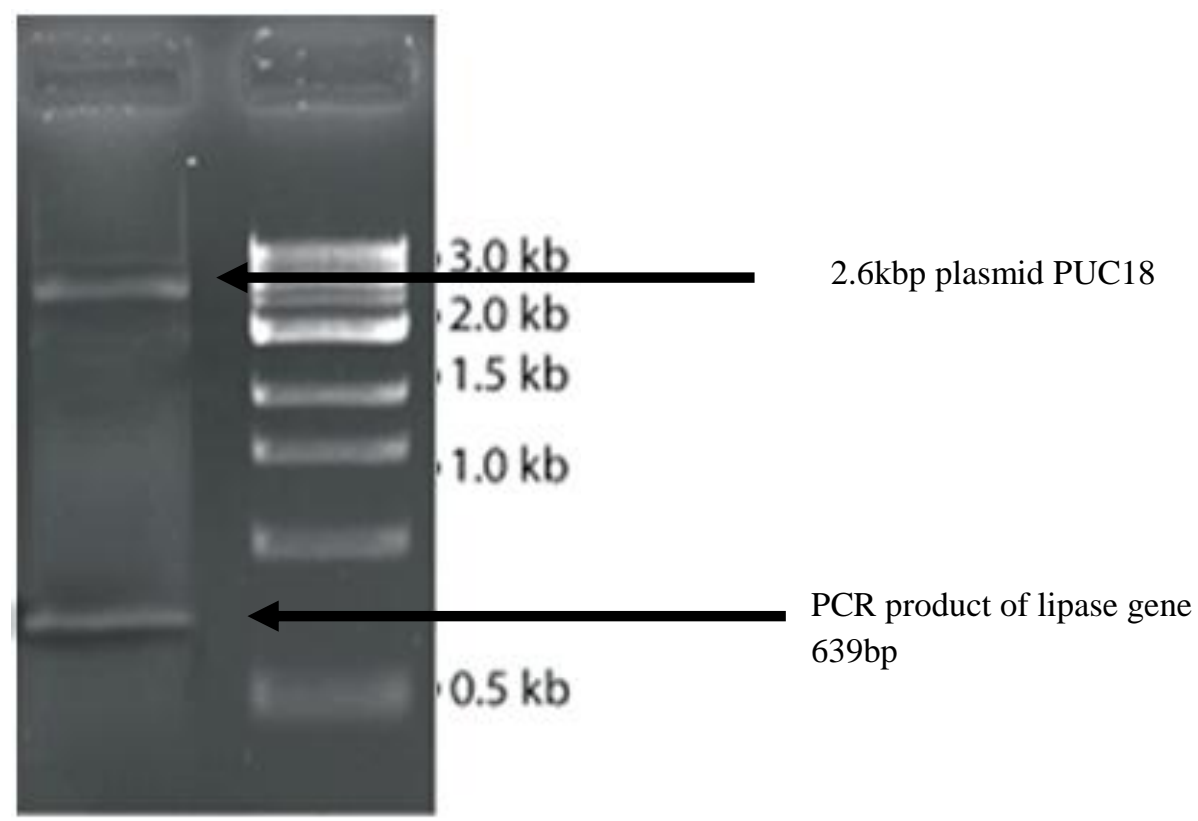

Figure :-conformation of the recombinant colonies

Conformation of recombinant colonies

lane 1 restricted plasmid(plasmid +lipase gene) that has been successfully separated by using restriction enzymes (BamHI and EcoRI). 
By using sequecnce of the lipase gene in Bacillus species taken from NCBI website, the primers are designed to amplify the lipase gene from Bacillus sp. The designed primers have the restriction sites as well in both sides of the primers of BamHI and EcoRI. The PCR product was successfully amplified by using optimizes PCR cycle. Positive transformants shows white colonies with associated antibiotic agar after overnight incubation at $37{ }^{\circ} \mathrm{C}$. The positive clones were streaked onto triolein-LB agar to screen for true lipase producers and were incubated overnight at 37

${ }^{\circ} \mathrm{C}$. The recombinant clones formed an intense blue color on the triolein-LB agar plate.

\section{References:-}

1. Bandow, J.E., H. Brtz, M. Hecker. "Bacillus subtilis Tolerance of Moderate Concentrations of Rifampin Involves the B-Dependent General and Multiple Stress Response". Journal of Bacteriology. 2002 January; 184(2): 459467.

2. Dartois V, Baulard A, Schanck K, Colson C. Cloning, nucleotide sequence and expression in Escherichia coli of a lipase gene from Bacillus subtilis 168.1992 Jul 15;1131(3):253-60.

3. Dartois V, Coppée JY, Colson C, Baulard A. Genetic analysis and overexpression of lipolytic activity in Bacillus subtilis.1994 May;60(5):1670-3.

4. Detry J, Rosenbaum T, Lütz S, Hahn D, Jaeger KE, Müller M, Eggert T. Biocatalytic production of enantiopure cyclohexane-trans-1,2-diol using extracellular lipases from Bacillus subtilis.Germany. 2006 Oct ;72(6): 1107-16. Epub 2006 Apr 4.

5. Dröge MJ, Boersma YL, van Pouderoyen G, Vrenken TE, Rüggeberg CJ, Reetz MT, Dijkstra BW, Quax WJ. Directed evolution of Bacillus subtilis lipase A by use of enantiomeric phosphonate inhibitors: crystal structures and phage display selection.2006 Jan;7(1):149-57.

6. http://www.molecular-plant-biotechnology.info/recombinant-DNA-technology/pUC18-19. microbiology and scnce $2^{\text {nd }}$ edition joan L. slonczewski,john w.foster.

7. Jørgensen S, Skov KW, Diderichsen B Cloning, sequence, and expression of a lipase gene from Pseudomonas cepacia: lipase production in heterologous hosts requires two Pseudomonas genes.1991 Jan;173(2):559-67.

8. Kamijo T, Saito A, Ema S, Yoh I, Hayashi H, Nagata R, Nagata Y, AndoA Molecular and enzymatic characterization of a subfamily I.4 lipase from an edible oil-degrader Bacillus sp. HH-01.2011 Feb;99(2):17987.

9. Klein M, Meens J, Freudl R. Functional characterization of the Staphylococcus carnosus SecA protein in Escherichia coli and Bacillus subtilis secA mutant strains.1995 Sep 15;131(3):271-7.

10. Detry J, Rosenbaum T, Lütz S, Hahn D, Jaeger KE, Müller M, Eggert T.Biocatalytic production of enantiopure cyclohexane-trans-1,2-diol using extracellular lipases from Bacillus subtilis. 2006 Oct; 72(6):1107Epub 2006 Apr 4.

11. Lodish H, Berk A, Zipursky SL Molecular Cell Biology. 4th edition, et al. New York,W. H. Freeman,2000.

12. $\underline{\mathrm{Lu} Y}, \underline{\mathrm{Lin}} \mathrm{Q}, \underline{\mathrm{Wang}} \mathrm{J}, \underline{\mathrm{Wu}} \mathrm{Y}, \underline{\mathrm{Bao}} \mathrm{W}, \underline{\mathrm{Lv} F}, \underline{\mathrm{Lu} Z}$ Overexpression and characterization in Bacillus subtilis of a positionally nonspecific lipase from Proteus vulgaris.2010Sep;37(9):919-25.

13. 13-Misset O, Gerritse G, Jaeger KE, Winkler U, Colson C, Schanck K, Lesuisse E, Dartois V, Blaauw $\underline{M}$, Ransac SThe structure-function relationship of the lipases from Pseudomonas aeruginosa and Bacillus subtilis.1994 Apr;7(4):523-9.

14. Perez, A.R., A. Abanes-De Mello, K. Pogliano. "SpoIIB Localizes to Active Sites of Septal Biogenesis and Spatially Regulates Septal Thinning during Engulfment in Bacillus subtilis". Journal of Bacteriology. 2000 February; 182(4): 1096 1108.

15. Rahman RN, Chin JH, Salleh AB, Basri M. Cloning and expression of a novel lipase gene from Bacillus sphaericus 205y. 2003 May; 269(2):252-60. Epub 2003 Mar 19.

16. Schaechter, M., J.L. Ingraham, F.C. Neidhardt. Microbe. (ASM Press, Washington, DC, 2006).

17. Wang L, Tai JD, Wang R, Xun EN, Wei XF, Wang L, Wang Z Enantioselective transesterification of glycidol catalysed by a novel lipase expressed from Bacillus subtilis.2010 May 10;56(1):1-6. 